\title{
MAPT promoter CpG island hypermethylation is associated with poor prognosis in patients with stage II colorectal cancer
}

This article was published in the following Dove Press journal: Cancer Management and Research

\author{
Chuntao Wang' \\ Yanliang Liu' \\ Wenyi Guo' \\ Xu Zhu' \\ Nita Ahuja ${ }^{2}$ \\ Tao Fu'
}

'Department of Gastrointestinal Surgery II, Key Laboratory of Hubei Province for Digestive System Disease, Renmin Hospital, Wuhan University, Wuhan, People's Republic of China; ${ }^{2}$ Department of Surgery, Yale School of Medicine, New Haven, CT, USA
Correspondence: Tao Fu

Department of Gastrointestinal Surgery II, Key Laboratory of Hubei Province for Digestive System Disease, Renmin Hospital, Wuhan University, 99

Zhangzhidong Road, Wuhan District 430060, Hubei Province, People's

Republic of China

Tel +8627880 4I9 II8I333

Email tfu00I@whu.edu.cn
Background: The methylation of microtubule-associated protein tau (MAPT) was first described in patients with Alzheimer's disease. In this study, we aim to determine if $M A P T$ promoter $\mathrm{CpG}$ island is hypermethylated and whether this signature could work as a prognostic marker for patients with stage II colorectal cancer (CRC).

Methods: $M A P T$ methylation level and $\mathrm{CpG}$ island methylator phenotype (CIMP) status were examined. The prognostic value of $M A P T$ methylation was analyzed using Cox regression analysis.

Results: Amongst stage II CRC patients ( $\mathrm{n}=107)$, hypermethylation of $M A P T$ promoter $\mathrm{CpG}$ island was seen in $23.4 \%$ of them. MAPT methylation was much more frequent in patients with age $\geq 60$ compared to age $<60(P<0.001)$. MAPT were preferentially methylated among proximal colon tumors or CIMP high tumors (both $P<0.001$ ). Five-year overall survival (OS) rates were $57.1 \%$ and $79.4 \%$ for patients with and without MAPT hypermethylation, respectively, HR=2.33 (95\% CI, 1.19-4.57; $P=0.014)$. MAPT hypermethylation remained an important prognostic variable for OS in multivariate analysis with a HR of $2.29(95 \% \mathrm{CI}$, 1.01-5.18; $P=0.047)$.

Conclusion: Our findings suggest that $M A P T$ is frequently methylated and hypermethylation is associated with worse prognosis in patients with stage II CRC.

Keywords: colorectal cancer, methylation, $M A P T$, prognosis

\section{Introduction}

Colorectal cancer (CRC), the second and third most common cancer in women and men, respectively, causes 832,000 deaths in 2015 worldwide. ${ }^{1}$ CRCs develop as a result of the accumulation of genetic and epigenetic alterations. $\mathrm{CpG}$ island methylator phenotype (CIMP) is one of the main mechanisms underlying CRC progression, which is characterized by the simultaneous methylation of cytosine residues in $\mathrm{CpG}$ islands from the promoter regions of multiple cancer-specific genes. ${ }^{2}$ Widespread changes in DNA methylation are common in CRC and may confer to oncogenesis through transcriptional silencing of tumor-suppressor genes. ${ }^{3}$

Microtubule-associated protein tau $(M A P T)$ is a gene located on chromosomal subband $17 \mathrm{q} 21 .{ }^{4}$ Tau protein encoded by $M A P T$ is among the best characterized microtubule-associated protein that promotes microtubule assembly and reduces microtubule instability. ${ }^{5}$ In addition to neurons, it is expressed at low levels in several non-neuronal cells. It has been shown to be involved in a number of neurodegenerative disorders including Alzheimer's disease, Parkinson's disease, 
and progressive supranuclear palsy, etc. The ability of tau to induce microtubule polymerization ${ }^{6}$ and its interaction with actin $^{7}$ indicates a possible role for tau in tumor cell migration and invasion. However, the function of tau in cancer remains relatively unexplored.

Recently, methylation of the MAPT promoter has been reported in a number of human diseases, including Alzheimer's disease, ${ }^{8}$ Parkinson's, ${ }^{9}$ and prostate cancer. ${ }^{10}$ However, the methylation status of MAPT and its influence on prognosis in CRC remains unclear. The goal of this study was to assess the methylation of MAPT promoter $\mathrm{CpG}$ island to determine its prognostic value in a cohort with 107 stage II CRC patients.

\section{Materials and methods}

\section{Subjects for methylation analysis}

Colorectal tissue samples were acquired by surgical resection from 107 patients (47 male and 60 female) with stage II CRC at the Johns Hopkins Hospital and the Johns Hopkins Bayview Hospital between 1995 and 2009. The median age was 67.8 years (range, 37-90 years). Tissue samples were available from all patients for molecular analysis; in 50 of these samples, a matched nontumor colorectal tissue was also obtained that was at least $2 \mathrm{~cm}$ distant from the tumor and in which cancer cell infiltration was ruled out by histologic review. Patients who were willing to participate provided written informed consent. This study was with approval from the Institutional Review Board and in accordance with Health Insurance Portability and Accountability Act regulations.

\section{MAPT methylation analysis by quantitative real-time methylation-specific PCR (Q-MSP)}

Q-MSP was used to assess MAPT methylation in primary tumors. Primers were designed using MSPprimer. ${ }^{11}$ Sequences are listed in Table 1. DNA was extracted and 1 $\mu \mathrm{g}$ was used for bisulfite conversion with the EZ DNA methylation Kit (Zymo Research). The Q-MSP was carried out in duplicates in 96-well plates using a total reaction volume of 20 $\mu \mathrm{L}$ including $10.0 \mu \mathrm{L}$ of $2 \times$ Power SYBR Green PCR Master Mix (Applied Biosystems), 2.5 pmol each of forward and reverse primers, and $2 \mu \mathrm{L}$ of DNA template. Fragments were amplified at $95^{\circ} \mathrm{C}$ for 10 mins, and 40 cycles of $95^{\circ} \mathrm{C}$ for $15 \mathrm{~s}$ followed by $60^{\circ} \mathrm{C}$ for $60 \mathrm{~s}$ using the Applied Biosystems 7500 One-Step Plus Real-Time PCR System. Dissociation curve analysis was performed to confirm the specificity of 
amplicons. Cycle threshold $(\mathrm{Ct})$ values were used to calculate methylation index (MI) using the following formula: $\mathrm{MI}=100 /$ $\left[1+2^{(\mathrm{Ctm}-\mathrm{Ctu})}\right]$. Ctm and $\mathrm{Ctu}$ indicate $\mathrm{Ct}$ value of the probes specific for the methylated and unmethylated states, respectively.

\section{CIMP methylation status analysis by methylight}

A 5-gene signature including $C A C N A 1 G, I G F 2$, NEUROG1, RUNX3, and SOCS1 was used to assess CIMP methylation status in tumor tissues. ${ }^{12}$ Methylation was quantified using MethyLight. ${ }^{12}$ Alu was used as a normalization control. A 5' FAM fluorophore, a 3' IBFQ quencher, and an internal ZEN quencher (Integrated DNA Technologies) were used for all CIMP probes. ${ }^{13}$ DNA methylation was calculated as percent of methylated reference $(\mathrm{PMR})=100 \times[($ methylated reaction/Alu $)$ sample/ (methylated reaction/Alu)M.SssI-reference)]. Genes were considered methylated when $P M R \geq 0$. When at least three of the five studied markers were methylated, the samples were considered CIMP high. ${ }^{12}$

\section{Statistical analysis}

For statistical analyses, the SPSS 18.0 (SPSS, Chicago, IL, USA) was used. Determination of cutoff values was made by the receiver-operator characteristics (ROC) curve. The area under the curve and the best sensitivity and specificity were then computed. The comparison of clinicopathologic factors was analyzed using the $\chi^{2}$ tests. Results were considered significant when $P<0.05$. The Kaplan-Meier method and log-rank test were used to estimate survival. Univariate and multivariate hazard ratios (HRs) were determined by using cox proportional hazard regression models. Overall survival (OS) was defined as the time from cancer diagnosis until death of all causes.

\section{Results}

\section{Methylation analysis}

DNA extraction and methylation analyses were successful in all 107 patients. Cutoff value of MI to separate all 107 cases into two groups (low-risk group and high-risk group) was calculated by using ROC analysis. Optimal cutoff was determined by maximizing the sensitivity and specificity. Therefore, tumors were dichotomized into both a unhypermethylated group $(\mathrm{MI}<10)$ and a hypermethylated group $(\mathrm{MI} \geq 10)$. Samples were hypermethylated in 25 cases $(23.4 \%)$ of the 107 patients. To confirm that these methylation consequences were specific to tumor tissue, we re-measured methylation levels of $M A P T$ in 50 tumor samples in parallel with their paired normal colonic mucosa tissues. $M A P T$ was hypermethylated in 11 of these tumors and no methylation was found in matched normal sample. The MI values of tumor were 28.4, 18.4, 74.7, 14.6, 10.0, 27.2, 31.0, 13.9, 28.3, 34.7, and 93.7 .

\section{Methylation and clinicopathological features}

Associations between $M A P T$ methylation status and patient clinicopathological features were examined. No significant difference was found in the distribution of patients with positive or negative hypermethylation of $M A P T$ in terms of gender, lymph nodes examined, tumor differentiation, or pT4. However, MAPT hypermethylation was much more common in patients with age $\geq 60(P<0.001$, Table 2$)$ and in proximal colon tumors $(P<0.001$, Table 2$)$. $M A P T$ hypermethylation was also strongly associated with CIMP status $(P<0.001$, Table 2$)$.

\section{Methylation and survival}

Survival analyses were conducted to assess the prognostic role of MAPT methylation. Among 107 eligible patients with adequate follow-up, there were 40 deaths (37.4\%). Five-year OS was significantly lower in MAPT-hypermethylated cases than $M A P T$-unhypermethylated cases (57.1\% vs 79.4\%; log-rank $P=0.011$ ) in Kaplan-Meier analysis (Figure 1). MAPT hypermethylation was associated with a significant decrease in OS (HR: 2.33; 95\% CI: $1.19-4.57 ; P=0.014$ ) in univariate Cox regression analysis. $M A P T$ hypermethylation remained significantly associated with OS (HR: 2.29; 95\% CI: 1.01-5.18; $P=0.047$ ) in multivariate analysis (Table 3 ).

\section{Discussion}

In this study, we examined the methylation status of $M A P T$ promoter $\mathrm{CpG}$ island and its possible prognostic value in patients with stage II CRC. We demonstrate here for the first time that $M A P T \mathrm{CpG}$ island of promoter is hypermethylated in $23.4 \%$ of patients with stage II CRC and $M A P T$ methylation was absent from a subgroup of paired normal colorectal mucosa, confirming that this methylation is tumor specific. Importantly, this event was unequally distributed among different ages; MAPT methylation was much more common in patients with age $\geq 60$ than in patients with age $<60$. Furthermore, $M A P T$ 
Table 2 Differential clinicopathologic features of colorectal cancer according to MAPT methylation status

\begin{tabular}{|c|c|c|c|c|c|}
\hline Variables & & $\begin{array}{l}\text { Total } n=107 \\
(\%)\end{array}$ & $\begin{array}{l}\text { MAPT-M } \\
(\%)\end{array}$ & $\begin{array}{l}\text { MAPT-U } \\
(\%)\end{array}$ & $P$-value \\
\hline Age (years) & $\begin{array}{l}<60 \\
\geq 60\end{array}$ & $\begin{array}{l}33(30.8) \\
74(69.2)\end{array}$ & $\begin{array}{l}\text { I (4.0) } \\
24(96.0)\end{array}$ & $\begin{array}{l}32(39.0) \\
50(61.0)\end{array}$ & 0.000 \\
\hline Sex & $\begin{array}{l}\text { Male } \\
\text { Female }\end{array}$ & $\begin{array}{l}47(43.9) \\
60(56.1)\end{array}$ & $\begin{array}{l}8(32.0) \\
17(68.0)\end{array}$ & $\begin{array}{l}39(47.6) \\
43(52.4)\end{array}$ & 0.170 \\
\hline Location & $\begin{array}{l}\text { Proximal } \\
\text { Distal }\end{array}$ & $\begin{array}{l}55(51.4) \\
52(48.6)\end{array}$ & $\begin{array}{l}21(84.0) \\
4(16.0)\end{array}$ & $\begin{array}{l}34(4 I .5) \\
48(58.5)\end{array}$ & 0.000 \\
\hline Lymph nodes examined & $\begin{array}{l}\geq 12 \\
<12\end{array}$ & $\begin{array}{l}74(69.2) \\
33(30.8)\end{array}$ & $\begin{array}{l}20(80.0) \\
5(20.0)\end{array}$ & $\begin{array}{l}54(65.9) \\
28(34.1)\end{array}$ & 0.180 \\
\hline Differentiation & $\begin{array}{l}\text { Well to moderate } \\
\text { Poor }\end{array}$ & $\begin{array}{l}89(83.2) \\
18(16.8)\end{array}$ & $\begin{array}{l}20(80.0) \\
5(20.0)\end{array}$ & $\begin{array}{l}69(84.1) \\
13(15.9)\end{array}$ & 0.628 \\
\hline pT4 & $\begin{array}{l}\text { No } \\
\text { Yes }\end{array}$ & $\begin{array}{l}96(89.7) \\
11(10.3)\end{array}$ & $\begin{array}{l}24(96.0) \\
\text { I }(4.0)\end{array}$ & $\begin{array}{l}72(87.8) \\
10(12.2)\end{array}$ & 0.452 \\
\hline CIMP & $\begin{array}{l}\text { Low } \\
\text { High }\end{array}$ & $\begin{array}{l}83(77.6) \\
24(22.4)\end{array}$ & $\begin{array}{l}9(36.0) \\
16(64.0)\end{array}$ & $\begin{array}{l}74(90.2) \\
8(9.8)\end{array}$ & 0.000 \\
\hline
\end{tabular}

Abbreviations: CIMP, CPG island methylator phenotype; MAPT-U, MAPT-unhypermethylated; MAPT-M, MAPT-hypermethylated.

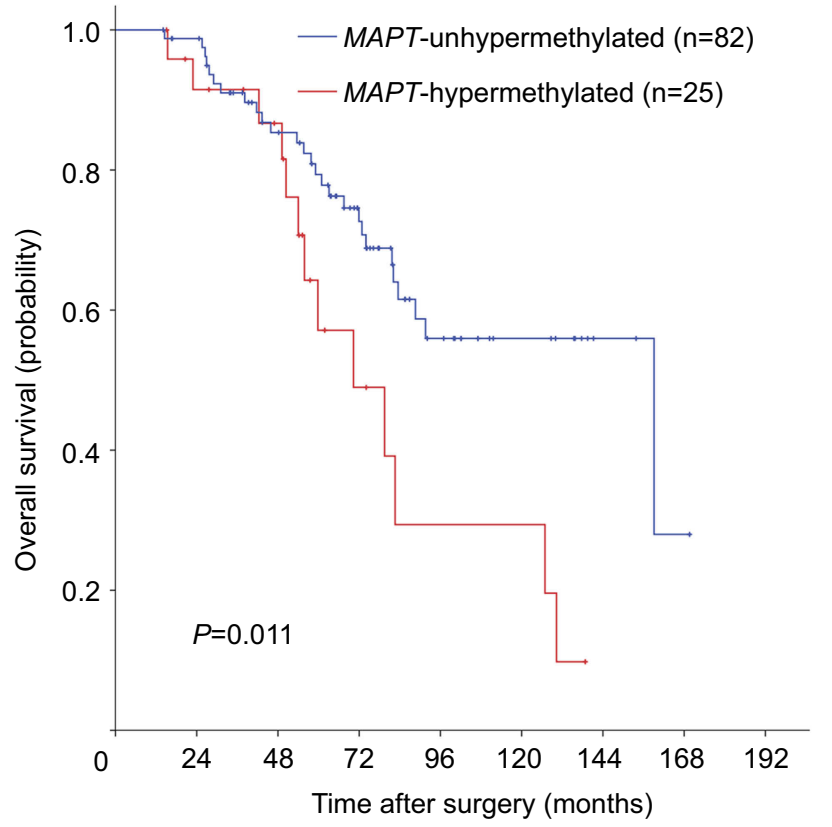

Figure I Kaplan-Meier survival estimates of overall survival between groups classified by MAPT methylation status in patients with stage II colorectal cancer. $P$ values were based on the log-rank test.

methylation was strongly associated with tumor location and CIMP status. MAPT appears to be preferentially methylated among proximal colon tumors or CIMP high tumors. Most important is that we highlight the negative and independent prognostic effect of MAPT hypermethylation on prognosis in patients with CRC using qMSP.
Pusztai et al previously assessed tau protein expression in primary tumors from 1942 patients with breast cancer by using tissue microarrays. They found $43 \%$ of patients were tau positive. Tau positivity was correlated with lower histologic grade and associated with better disease-free survival and $O S$ both in univariate and multivariate analyses. $^{14}$ Hristodorov et al cloned tau in-frame with EGF using EGF as a binding component to test the efficacy of tau. The tau-mediated and proliferation-dependent antitumor activity was demonstrated in vitro using EGF receptor-overexpressing breast cancer cell lines and in vivo using a mouse xenograft model. ${ }^{15}$ This holds true in lymphomas by using similar technique, in which study they noted tau could induce apoptosis when delivered to rapidly proliferating cancer cells. ${ }^{16}$ Collectively, these observations provide strong evidence that MAPT is a candidate tumor-suppressor gene.

In contrast, an analysis of tau expression in 102 primary breast carcinomas and matched metastases reveals that $52 \%$ hold tau expression in metastases and $26 \%$ show significantly elevated tau expression during disease progression. They also demonstrated that endogenic tau localized to microtentacles and was both essential and adequate to promote microtentacle extension in detached breast tumor cells, and tau-induced microtentacles enhanced the suspended cells to reattach and the circulating tumor cells to retain in lung capillaries. ${ }^{17}$ These results 
Table 3 Univariate and multivariate Cox proportional hazard analysis of overall survival

\begin{tabular}{|c|c|c|c|c|c|}
\hline \multirow[t]{3}{*}{ Variables } & \multirow[t]{3}{*}{ Total $\mathbf{n}$} & \multicolumn{4}{|l|}{ os } \\
\hline & & \multicolumn{2}{|l|}{ Univariate } & \multicolumn{2}{|l|}{ Multivariate } \\
\hline & & HR (95\% Cl) & $P$-value & HR (95\% Cl) & $P$-value \\
\hline Age (years) & & & 0.072 & & 0.234 \\
\hline$<60$ & 33 & I.00 (Referent) & & 1.00 (Referent) & \\
\hline$\geq 60$ & 74 & $2.04(0.94-4.45)$ & & $1.68(0.72-3.92)$ & \\
\hline Sex & & & 0.824 & & \\
\hline Male & 47 & I.00 (Referent) & & & \\
\hline Female & 60 & $0.93(0.50-1.74)$ & & & \\
\hline Location & & & 0.439 & & 0.656 \\
\hline Proximal & 55 & I.00 (Referent) & & 1.00 (Referent) & \\
\hline Distal & 52 & $0.78(0.42-1.46)$ & & $1.18(0.56-2.48)$ & \\
\hline Lymph nodes examined & & & 0.514 & & 0.433 \\
\hline$\geq 12$ & 74 & I.00 (Referent) & & I.00 (Referent) & \\
\hline$<12$ & 33 & $1.24(0.65-2.38)$ & & $\mathrm{I} .33(0.65-2.7 \mathrm{I})$ & \\
\hline Differentiation & & & 0.463 & & 0.804 \\
\hline Well to moderate & 89 & I.00 (Referent) & & 1.00 (Referent) & \\
\hline Poor & 18 & $0.70(0.28-1.80)$ & & $0.88(0.3 \mathrm{I}-2.49)$ & \\
\hline pT4 & & & 0.326 & & 0.689 \\
\hline No & 96 & I.00 (Referent) & & 1.00 (Referent) & \\
\hline Yes & 11 & $0.55(0.17-1.80)$ & & $0.77(0.2 \mathrm{I}-2.83)$ & \\
\hline MAPT hypermethylation & & & 0.014 & & 0.047 \\
\hline No & 82 & I.00 (Referent) & & 1.00 (Referent) & \\
\hline Yes & 25 & $2.33(1.19-4.57)$ & & $2.29(1.01-5.18)$ & \\
\hline
\end{tabular}

suggest that tau may augment, rather than inhibit tumor development.

Previous studies showed that tau was a multifunctional protein, whose role depended on its localization. For example, it mediates microtubule polymerization and stabilization in the cytoskeleton, ${ }^{18}$ while involved in DNA protection and the promotion of chromosomal stability within the nucleus. ${ }^{19,20}$ In addition, the MAPT primary transcript contains 16 exons, alternative splicing of these exons results in at least six tau isoforms. ${ }^{21,22}$ Each of these isoforms is likely to have specific physiological roles since they are differentially expressed over development. Moreover, the longest tau isoform have 80 putative Ser or Thr phosphorylation sites. Phosphorylation of these sites differentially influences its biological function. ${ }^{23}$ Taken together, localizations, differential splicing, and phosphorylation may give rise to a complex pattern of interacting tau isoforms with tumor-suppressor or oncogenic functions. Therefore, for facilitating our comprehension of tau's function in cancer, further studies should investigate its isoforms and the effect of phosphorylation of tau as the microarray probes or the antibody used were directed against shared domains and were not aimed at phosphorylation status.

Traditional risk factors for CRC include $<12$ lymph nodes examined, poor histologic differentiation, pT4 lesions, intestinal obstruction or perforation, and lymphovascular invasion. These high-risk features are also recommended for clinical decisions regarding adjuvant therapy in stage II CRC. However, these features have mainly been accepted from indirect evidence in stage III CRC studies and their clinical performance has limitations. As shown in our present study, none of the risk factors including $<12$ lymph nodes examined, tumor differentiation, or pT4 lesions, was associated with OS in patients with stage II CRC.

To our knowledge, the expression and methylation of $M A P T$ in colon tissue or CRC has not been reported to date. However, a study analyzing tau levels in tissue samples from patients with Alzheimer's disease revealed that total tau protein has the highest levels in brain, 
followed by submandibular gland, sigmoid colon, liver, scalp, and abdominal skin. ${ }^{24}$ We searched the Cancer Genome Atlas (TCGA) database (https://cancergenome. nih.gov/) and found that 434 cases of primary CRC samples had both MAPT gene expression and methylation data. $M A P T$ gene was differentially expressed and methylated (data not shown). In our series, $M A P T$ promoter $\mathrm{CpG}$ island is frequently methylated in stage II CRC. Poorer prognosis is found in patients with $M A P T$ hypermethylated tumors regardless of several clinicopathological parameters. It is also important to consider that the inclusion of other methylated genes in addition to MAPT in a multigene or multimolecular prediction score can improve its prognostic values. Further studies to evaluate the function of tau in CRC are currently in progress.

\section{Abbreviations}

$M A P T$, microtubule-associated protein tau; $\mathrm{CRC}$, colorectal cancer; OS, overall survival; $\mathrm{Ct}$, threshold cycles; FFPE, formalin-fixed and paraffin-embedded.

\section{Acknowledgments}

We thank Kathy Bender and Joann Murphy at the Johns Hopkins Hospital for administrative support. We also thank Sharon Metzger-Gaud, Theresa Sanlorenzo-Caswell, and the Johns Hopkins Cancer Registry for assistance with the primary cancer databases. This work was supported by the Scientific Research Foundation for the Returned Overseas Chinese Scholars, State Education Ministry of China.

\section{Disclosure}

Nita Ahuja has received grant funding from Cepheid and Astex and has served as consultant to Ethicon. She has licensed methylation biomarkers to Cepheid and has a patent Predicting Response to Epigenetic Drug Therapy pending to JHU, a patent Diagnostic Test for the Early Detection of Pancreatic Cancer with royalties paid to Cepheid, and a patent Markers for Improved Detection of Breast Cancer issued. The authors report no other conflicts of interest in this work.

\section{References}

1. Global Burden of Disease Cancer C, Fitzmaurice C, Allen C, et al. Global, regional, and national cancer incidence, mortality, years of life lost, years lived with disability, and disability-adjusted life-years for 32 Cancer Groups, 1990 to 2015: a systematic analysis for the Global Burden of Disease Study. JAMA Oncol. 2017;3:524-548. doi:10.1001/ jamaoncol.2016.5688
2. Toyota M, Ahuja N, Ohe-Toyota M, Herman JG, Baylin SB, Issa JP. $\mathrm{CpG}$ island methylator phenotype in colorectal cancer. Proc Natl Acad Sci. 1999;96:8681-8686. doi:10.1073/pnas.96.15.8681

3. Berman BP, Weisenberger DJ, Aman JF, et al. Regions of focal DNA hypermethylation and long-range hypomethylation in colorectal cancer coincide with nuclear lamina-associated domains. Nat Genet. 2011;44:40-46. doi:10.1038/ng.969

4. Neve RL, Harris P, Kosik KS, Kurnit DM, Donlon TA. Identification of cDNA clones for the human microtubule-associated protein tau and chromosomal localization of the genes for tau and microtubuleassociated protein 2. Brain Res. 1986;387:271-280. doi:10.1016/ 0169-328x(86)90033-1

5. Arendt T, Stieler JT, Holzer M. Tau and tauopathies. Brain Res Bull. 2016;126:238-292. doi:10.1016/j.brainresbull.2016.08.018

6. Drubin DG, Kirschner MW. Tau protein function in living cells. $J$ Cell Bio. 1986;103:2739-2746. doi:10.1083/jcb.103.6.2739

7. Yu JZ, Rasenick MM. Tau associates with actin in differentiating PC12 cells. Faseb J. 2006;20:1452-1461. doi:10.1096/fj.05-5206com

8. Iwata A, Nagata $\mathrm{K}$, Hatsuta $\mathrm{H}$, et al. Altered $\mathrm{CpG}$ methylation in sporadic Alzheimer's disease is associated with APP and MAPT dysregulation. Hum Mol Genet. 2014;23:648-656. doi:10.1093/hmg/ddt451

9. Coupland KG, Mellick GD, Silburn PA, et al. DNA methylation of the MAPT gene in Parkinson's disease cohorts and modulation by vitamin E in vitro. Mov Disord. 2014;29:1606-1614. doi:10.1002/mds.25784

10. Shui IM, Wong CJ, Zhao S, et al. Prostate tumor DNA methylation is associated with cigarette smoking and adverse prostate cancer outcomes. Cancer. 2016;122:2168-2177. doi:10.1002/cncr.30045

11. Brandes JC, Carraway H, Herman JG. Optimal primer design using the novel primer design program: mSPprimer provides accurate methylation analysis of the ATM promoter. Oncogene. 2007;26:6229-6237. doi:10.1038/sj.onc.1210433

12. Weisenberger DJ, Siegmund KD, Campan M, et al. CpG island methylator phenotype underlies sporadic microsatellite instability and is tightly associated with BRAF mutation in colorectal cancer. Nat Genet. 2006;38:787-793. doi:10.1038/ng1834

13. Fu T, Pappou EP, Guzzetta AA, et al. CpG island methylator phenotype-positive tumors in the absence of MLH1 methylation constitute a distinct subset of duodenal adenocarcinomas and are associated with poor prognosis. Clin Cancer Res. 2012;18:4743-4752. doi:10.1158/1078-0432.CCR-12-0707

14. Pusztai L, Jeong JH, Gong Y, et al. Evaluation of microtubuleassociated protein-tau expression as a prognostic and predictive marker in the NSABP-B 28 randomized clinical trial. J Clin Oncol. 2009;27:4287-4292. doi:10.1200/JCO.2008.21.6887

15. Hristodorov D, Mladenov R, Pardo A, et al. Microtubule-associated protein tau facilitates the targeted killing of proliferating cancer cells in vitro and in a xenograft mouse tumour model in vivo. Br J Cancer. 2013;109:1570-1578. doi:10.1038/bjc.2013.457

16. Hristodorov D, Nordlohne J, Mladenov R, et al. Human microtubuleassociated protein tau mediates targeted killing of CD30(+) lymphoma cells in vitro and inhibits tumour growth in vivo. $\mathrm{Br} J$ Haematol. 2014;164:251-257. doi:10.1111/bjh.12626

17. Matrone MA, Whipple RA, Thompson K, et al. Metastatic breast tumors express increased tau, which promotes microtentacle formation and the reattachment of detached breast tumor cells. Oncogene. 2010;29:3217-3227. doi:10.1038/onc.2010.68

18. Drechsel DN, Hyman AA, Cobb MH, Kirschner MW. Modulation of the dynamic instability of tubulin assembly by the microtubule-associated protein tau. Mol Bio Cell. 1992;3:1141-1154. doi:10.1091/mbc.3.10.1141

19. Rossi G, Dalpra L, Crosti F, et al. A new function of microtubuleassociated protein tau: involvement in chromosome stability. Cell Cycle. 2008;7:1788-1794. doi:10.4161/cc.7.12.6012

20. Violet M, Delattre L, Tardivel M, et al. A major role for Tau in neuronal DNA and RNA protection in vivo under physiological and hyperthermic conditions. Front Cell Neurosci. 2014;8:84. doi:10.3389/fncel.2014. 00052 
21. Goedert M, Spillantini MG, Potier MC, Ulrich J, Crowther RA. Cloning and sequencing of the cDNA encoding an isoform of microtubule-associated protein tau containing four tandem repeats: differential expression of tau protein mRNAs in human brain. Embo J. 1989;8:393-399.

22. Goedert M, Wischik CM, Crowther RA, Walker JE, Klug A. Cloning and sequencing of the cDNA encoding a core protein of the paired helical filament of Alzheimer disease: identification as the microtubule-associated protein tau. Proc Natl Acad Sci. 1988;85:4051-4055. doi:10.1073/pnas.85.11.4051
23. Sergeant N, Delacourte A, Buee L. Tau protein as a differential biomarker of tauopathies. Biochim Biophys Acta. 2005;1739:179197. doi:10.1016/j.bbadis.2004.06.020

24. Dugger BN, Whiteside CM, Maarouf CL, et al. The presence of select tau species in human peripheral tissues and their relation to Alzheimer's disease. J Alzheimer's Dis. 2016;54:1249. doi:10.3233/ JAD-169007

\section{Publish your work in this journal}

Cancer Management and Research is an international, peer-reviewed open access journal focusing on cancer research and the optimal use of preventative and integrated treatment interventions to achieve improved outcomes, enhanced survival and quality of life for the cancer patient.
The manuscript management system is completely online and includes a very quick and fair peer-review system, which is all easy to use. Visit http://www.dovepress.com/testimonials.php to read real quotes from published authors. 